\title{
Cultural Specificity on Perception towards Educational Environment and Mental Health among Chinese and U.S. Adolescents
}

\author{
Ying Liu ${ }^{1}$, Cody Ding ${ }^{2} \&$ Shu Peng ${ }^{3}$ \\ ${ }^{1}$ School of Osteopathic Medicine, Rowan University, Stratford, New Jersey, USA \\ ${ }^{2}$ College of Education, University of Missouri-St. Louis, St. Louis, Missouri, USA \\ ${ }^{3}$ The Essential Learning Group, Shanghai, China \\ Correspondence: Ying Liu, Academic Affairs, Rowan University School of Osteopathic Medicine, One Medical \\ Center Drive, Stratford, New Jersey, 08084, USA. Tel: 1-856-566-2875. E-mail: liu26@rowan.edu
}

Received: April 17, 2014

Accepted: May 4, 2014

Online Published: June 13, 2014

doi:10.5539/jedp.v4n2p35

URL: http://dx.doi.org/10.5539/jedp.v4n2p35

\begin{abstract}
This study examined cultural influence on perceptions towards educational environment and mental health behaviors among adolescents in grades 7 and 10 from both China and the U.S. Utilizing the perspective of cultural activity theory, we explored the behavioral patterns with respect to adolescents' perceived school climate (school, teacher and peer), perceived parental involvement, time spent watching TV and using computer, and overall assessment of mental health. The results not only indicated significant differences in these factors including various aspects of school climate, parental involvement, media consumption and self-reported mental health status, but also suggested unique developmental trend among Chinese adolescents. School, teachers, peers and parents were found to be significant indicators of adolescents' mental health. The findings were discussed from the perspective of cultural activity theory, along with limitations and future directions.
\end{abstract}

Keywords: cultural activity theory, mental health, cross-culture

\section{Introduction}

There is convincing evidence that the social, political, and economical changes in China have had tremendous impacts on the lives of adolescents today, particularly in the cities where Western culture and Westernization are more common among youth. As suggested by some researchers, this influence of Western cultures on young adults' lives is a direct by-product of economic globalization, and it changes adolescents' interests, lifestyles, and more importantly, some of their values (Larson, 2002). Evidence suggests increasing materialism in adolescents' values and aspirations, with strong emphasis on brand, Western culture, or monetary values. For example, current adolescents in major Chinese cities find it fashionable to be consumers and owners of brand names such as Nike ${ }^{\circledR}, \mathrm{Nestle}^{\circledR}, \mathrm{Coca}_{\mathrm{Cola}}{ }^{\circledR}$, Polo $^{\circledR}$, and Levi Strauss ${ }^{\circledR}$ (Larson, 2002). There are many Chinese adolescents who celebrate their birthdays at McDonald's ${ }^{\circledR}$ or Pizza Hut ${ }^{\mathbb{B}}$, spend Valentine's Day with their lovers, dress up for Halloween parties, and celebrate Thanksgiving and Christmas. Moreover, wide availability of computer and Internet allows adolescents to access Western media and culture in ways never before experienced.

The implications of the Western cultural influence on Chinese adolescents, particularly the U.S., are profound. On one hand, adolescents are exposed to wide ranges of new information and new ideas; on the other, they may be easily "culturally polluted", i.e., their perceptions about Western lifestyles are likely to be distorted because of their inabilities to filter the appropriate information. Since they have never experienced adolescent life in a Western environment and are limited in their cognitive perceptions, it is possible that they tend to take what they see via media as the reality of Western adolescent life-lots of fun, no need to study, free expression, money, sex, and parties. Although there are quite a few research studies conducted on Chinese adolescents in recent years (e.g., Chen, Greenberger, Farruggia, Bush, \& Dong, 2003; Cheung \& McBride-Chang, 2007; Ma, Cheung, \& Shek, 2007; Wong, Wong, \& Mok, 2006), there is still much to learn about the regular social behaviors, activities, and well-being of adolescents in current China, particularly in mainland China, in the context of the profound influence of the U.S. economy and culture. The social and economic transformation of China in recent 
years may be of particular interest to developmental, social, and cultural psychologists because it may help interpret the considerable developmental and cross-cultural research that has emerged from China over the years. Given the number of societies around the world undergoing a similar transition (Brown, Larson, \& Saraswathi, 2002), systematic exploration of the effects of such drastic transition is of even broader significance. The primary purpose of the study was to examine cultural differences or specificity between China and the U.S. with respect to adolescents' perceptions of their education environment, their mental health status, and if new media and technology might have impact on their mental health.

\subsection{Theoretical Framework}

The current study is heavily grounded in the conceptualization of cultural psychology from the perspective of cultural activity theory (Ratner, 2002; Vygotsky, 1997). Cultural activity theory (CAT), also known as cultural historical activity theory (CHAT), is adaptable and applicable to many disciplines based on broad developmental dimensions. CAT views human behaviors as complex systems, and it studies individual subject and social reality through mediating activity. Instead of interacting directly with environment, the development of complex systems is culturally mediated through tangible and psychological tools (Vygotsky, 1997).

According to this theoretical framework, adolescents may behave (or be perceived to behave) in certain ways in different cultural contexts and modify their behaviors not because of biological imperatives but as a result of cultural activities. For instance, school normally includes class attendance, interaction with teachers and fellow students, expectations from teachers and parents, time spent on school work or other activities, etc. However, these universal school activities may take on some distinctive characteristics in different cultural contexts. It is, therefore, important to study these specific socially-created characteristics because they impart unique features to student psychological phenomena, such as the ways in which students treat each other, react to teachers, or perceive school in general. Psychological phenomena are cultural in that they are shared by a number of individuals and integrated with other social artifacts and social culture to create their content, mode of operation, and dynamic relationships (Ratner, 2002). Culture-specific practices serve to motivate individuals toward certain goals, to instruct them to behave in specific ways, and to potentiate perceptions that would not develop in social isolation. Such practices are of particular importance to adolescents, as they develop psychological processes and the capability of regulating themselves and others from the outside world. Some cross-cultural comparative research on adolescents has provided evidence of cross-cultural similarity in adolescent development (e.g., Barber \& Harmon, 2001; Chen \& Farruggia, 2002; Vazsonyi, 2003). From the perspective of CAT, the general forms of adolescent development are mediated, in a large part, by the extent to which different aspects of culture exert their influence on the adolescents' behaviors.

\subsection{School, Parents, Media and Adolescent Mental Health}

School climate plays key role in initiating and maintaining education improvement (Cohen, McCabe, Michelli, \& Pickeral, 2009; Noonan, 2004). It has been associated with academic achievement (Brand, Felner, Shim, Seitsinger, \& Dumas, 2003) and dropout rates by students' senior year (Barile, Donohue, Anthony, Baker, Weaver, \& Henrich, 2012; Lan \& Lanthier, 2003). More importantly, it has been found to protect against the development of risk behaviors in youth (Cunningham, 2007; Kuperminc, Leadbeater, Emmons, \& Blatt, 1997), to foster psychological health and well-being in school (Berkowtiz \& Bier, 2005; Catalano, Haggerty, Oesterle, Fleming, \& Hawkins, 2004), and to reduce depression, aggression and victimization (Loukas, Suzuki, \& Horton, 2006; Wilson, 2004). Given such importance, school climate has been targeted for improvement in programs for promoting mental health and preventing behavior problems (Adelman \& Taylor, 2010).

Although school climate has been extensively studied in the U.S., very little is known about school climate in China and how it influences adolescent mental health. In general, there seem to be fewer problems and more orderliness in Chinese classrooms. It is not completely surprising, as in Chinese culture both school and family highlight students' hard work and efforts, and prizing academic excellence (Chen \& Farruggia, 2002). The role of the teacher is one of authority, demanding the students' obedience and respect. Classroom activities focus on the maintenance of classroom order and the efficiency with which knowledge is transmitted (Ma et al., 2007).

Parents have also had their share of influence on adolescent mental health. Confucianism emphasizes self-perfection, honor to the family, and respect of parents (Hui, Sun, Chow, \& Chu, 2011). Chinese parents demand compliance and obedience from adolescent starting in an early age (Yau, Smetana, \& Metzger, 2009), although whether it has positive or negative impact on parent-child relationship is still open to debate. 
With emerging globalization and westernization that is occurring in China, not only do the majority of families own TV, but they also have gained access to so-called new media, computer, Internet, video games, etc. The diffusion of new technologies is happening so quickly that research on potential implications has been slow to catch up. It is believed that media use displaces important developmental activities (Anderson \& Bushman, 2001; Neuman, 1995). The more time adolescents spend on media, the less time they have for other healthy activities. There is also evidence of negative impact of computer and Internet use. It has been reported that about $40 \%$ of students who reside in large cities spend more than four hours a day playing computer games via the Internet and about $30 \%$ visit pornographic websites (Xilong, 2006).

\subsection{Hypotheses}

Rapid economic transformation of China, with reference to the same set of perceived behaviors in the U.S., provided a context for hypothesis testing of cultural specificity. We used the American students for comparison because the U.S. culture has influenced Chinese youngsters in unprecedented ways, as suggested by some early research (e.g., Mortimer \& Larson, 2002). Although economic and cultural influence of the U.S. is present and there may exist behavioral similarities among adolescents in the two countries, testing of cultural specificity is still important and helpful in understanding the unique challenges faced in each country.

Based on theoretical framework discussed previously, we first hypothesized that cultural environment or specificity would contribute to different patterns in adolescent social behaviors. Particularly, we would expect Chinese adolescents to demonstrate more positive attitude toward school than American adolescents, since education is viewed as a way to happiness in Chinese culture. Second, we would also expect them to feel more favorably about parental involvement in school. Third, we predicted that Chinese adolescents would report more positive mental health status in comparison with their peers in U.S., and such difference would be related to not only school and parents, but also media and technology.

To test the above hypotheses, we examined perceived social behavior that is most relevant to adolescent life: students' perceptions about school climate (i.e., about school, teachers, and fellow students), perceived parental involvement in school, and TV watching as well as computer usage. In addition, we examined adolescents' feelings towards happiness, loneliness, helplessness, and self-confidence. We employed these variables because they provided indicators of the essential ingredients for healthy development. The current study tested an important question of how adolescent mental health was shaped in different cultures and would contribute to cultural activity theory by understanding adolescent social development as a cultural process-a process in an environment with the interaction between U.S. influence and Chinese traditional culture.

\section{Methods}

\subsection{Participants and Data Source}

Data from China and the U.S. were available for the analysis. For the U.S. data, the current analysis included 3159 White students of seventh and tenth grades. These students were from a representative U.S. student population and their data were collected via the study of Health Behavior in School-aged Children (HBSC) in the 1997/1998 survey (Currie, Samdal, Boyce, \& Smith, 2001; World Health Organization, 2003). The original U.S. data included students of all races. Given that the Chinese data did not have students of different racial groups, in order to control for disparity in social behaviors and mental health status because of ethnic background, only the data from White students were included in analysis. The detailed description of HBSC study can be found in Currie et al. (2001).

Chinese data, which were collected in 2009, included 497 seventh and tenth graders from two large urban and surrounding areas in Northeast China. A battery of questionnaire that assessed adolescents' psychosocial development was administered to the participants in the classroom by classroom teacher. A consent form was obtained from each student before the data collection.

Although these students were from two different areas, they shared similar experiences of recent economic growth in China and their socialization processes were shaped by the same economic and cultural conditions. Chinese primary and secondary education systems consist of elementary school (6 years for grades 1 to 6 ), middle school ( 3 years for grades 7, 8, and 9), and high school ( 3 years for grades 10, 11, and 12). Table 1 shows summary statistics for demographic variables. 
Table 1. Summary statistics for demographic variables

\begin{tabular}{lll}
\hline Variable & China & U.S. \\
\hline $\begin{array}{l}\text { Sample size } \\
\text { Grade }\end{array}$ & 497 & 3159 \\
$\quad \% 7^{\text {th }}$ grade & 56.2 & 41.7 \\
$\quad \% 10^{\text {th }}$ grade & 43.8 & 58.3 \\
Gender & & \\
$\quad \%$ female & 52.8 & 53.6 \\
$\quad \%$ male & 47.2 & 46.4 \\
Residence location & & \\
$\quad \%$ large city & 33.9 & 14.8 \\
\% near a large city & 6.2 & 33.2 \\
\% town & 33.1 & 32.2 \\
\% rural area & 26.7 & 19.9 \\
\hline
\end{tabular}

\subsection{Instruments}

Based on our conceptualization of social activity and mental health, we have selected items that measured perceived school climate, parental involvement, TV watching and computer use, and mental health status. Table 2 shows the content and scale of these items, which were from the 1997/1998 study of Health Behavior in School-aged Children (HBSC). We selected these measures because they represented some of the key aspects of social life in which these students were actively involved.

Since the standard original HBSC questionnaire was developed in English, the questionnaire was translated into Chinese and was validated through a double-translation process according to the guidelines provided by Brislin (1986). After the translation-back-translation procedure, a small bilingual study was conducted to pilot test the translation accuracy of the newly translated instrument as well as to ensure the validity of the instrument in a culturally relevant and comprehensible form while maintaining the meaning of the original items.

Table 2. Items used in the study

\begin{tabular}{|c|c|c|}
\hline \multicolumn{3}{|l|}{ Perceived education environment } \\
\hline How do you feel about school at present? & Like it a lot (1) & Don't like it at all (4) \\
\hline $\begin{array}{l}\text { How often do you think that going to } \\
\text { school is boring? }\end{array}$ & Never (1) & Very often (5) \\
\hline The rules in this school are fair. & Strongly Agree (1) & Strongly Disagree (5) \\
\hline Our school is a nice place to be. & Strongly Agree (1) & Strongly Disagree (5) \\
\hline I belong in this school. & Strongly Agree (1) & Strongly Disagree (5) \\
\hline $\begin{array}{l}\text { Encouraged to express my views in my } \\
\text { class. }\end{array}$ & Strongly Agree (1) & Strongly Disagree (5) \\
\hline Our teachers treat us fairly. & Strongly Agree (1) & Strongly Disagree (5) \\
\hline When I need extra help, I can get it. & Strongly Agree (1) & Strongly Disagree (5) \\
\hline $\begin{array}{l}\text { My teachers are interested in me as a } \\
\text { person. }\end{array}$ & Strongly Agree (1) & Strongly Disagree (5) \\
\hline $\begin{array}{l}\text { My teacher expect too much of me at } \\
\text { school. }\end{array}$ & Strongly Agree (1) & Strongly Disagree (5) \\
\hline The students in my classes enjoy being & Never (1) & Always (5) \\
\hline
\end{tabular}


together.

Most of the students in my class are kind Never (1) and helpful.

Other students accept me as I am.

If I have problems at school, my parents are ready to help.

My parents are willing to come to school to talk to teachers.

My parents encourage me to do well at Never (1) school.

My parents expect too much of me at school.

\section{TV watching and computer use}

How many hours a day do you usually None (1) watch TV?

How many hours a week do you usually None (1) play computer games?

How many hours a week do you use a None (1) computer at home and at school, not counting computer games?

\section{Mental Health Measures}

In general, how do you feel about your life at present?

Do you ever feel lonely?

How often do you feel helpless?

How often do you feel confident?

\author{
Never (1) Always (5) \\ Never (1) Always (5) \\ Always (5) \\ Always (5)
}

Strongly disagree Stronglyagree (5)
(1)

More than 4 hours a day

(6)

10 hours or more (6)

10 hours or more (6)
Feel very happy (1) Not happy at all (4)

No (1) $\quad$ yes, very often (4)

Never (1) Always (5)

Never (1) Always (5)

\subsection{Analysis Design}

The primary goal of the study was to evaluate cultural influences on adolescent development. Such a test was conducted by examining what types of the socialization and mental health patterns emerged from the Chinese adolescents and to what extent these patterns were similar to or different from those of U.S. adolescents. We addressed these questions using multivariate analysis of variance (MANOVA). In the current analysis, we tested: (1) country differences, (2) grade level differences, and (3) gender differences across all individual measures. We used the individual items to provide more detailed picture of behavioral responses perceived.

We also performed logistic regression analysis to examine relations among education environment, computer use, and mental health status. In doing so, we created new scales by combining individual items. Internal consistency among these items was examined by calculating Cronbach's $\alpha$. Several items were removed from further analysis to ensure acceptable Cronbach's $\alpha$ values, which were set above 0.7 . Averages of individual items were then calculated and new scales were recoded before logistic regression analysis was conducted.

\section{Results}

\subsection{Hypothesis 1: Chinese Adolescents Report More Positive Attitude towards School than American Adolescents}

The results of MANOVA analysis seemed to support cultural specificity as promulgated by cultural activity theory. Specifically, there were statistically significant multivariate effects for country across each set of outcome measures (all $p$ values for Wilks' $\lambda$ is less than .001). Tables 3 to 6 indicated the specific univariate effect for each individual measure, along with mean, standard deviation, and effect size. 
Table 3 shows the averages of student perception of education environment by grade and country. In our model and following analysis, school climate consists of three core elements: school, teachers, and peers. Across all items on school climate, there was no significant gender difference (data not shown). However, the results suggested statistically significant differences among students in grades 7 and 10 from China and U.S. For all three elements, i.e., school, teachers and peers, Chinese students in both grades reported significantly more positive perception in all items but one (My teachers are interested in me as a person).

Table 3. Mean, standard deviation, and effect size of perceived school climate by grade and country

\begin{tabular}{|c|c|c|c|c|c|c|}
\hline & \multicolumn{3}{|c|}{$7^{\text {th }}$ Grade } & \multicolumn{3}{|c|}{$10^{\text {th }}$ Grade } \\
\hline & U.S. & China & Cohen's $d$ & U.S. & China & Cohen's d \\
\hline \multicolumn{7}{|l|}{ School } \\
\hline Like school a lot & $2.82(0.90)^{\mathrm{a}, \mathrm{b}}$ & $3.58(0.65)^{\mathrm{a}, \mathrm{b}}$ & 0.86 & $2.77(0.90)^{\mathrm{a}, \mathrm{b}}$ & $3.10(0.83)^{\mathrm{a}, \mathrm{b}}$ & 0.37 \\
\hline School is not boring & $2.67(1.13)^{\mathrm{a}, \mathrm{b}}$ & $4.34(0.82)^{\mathrm{a}, \mathrm{b}}$ & 1.51 & $2.50(1.05)^{\mathrm{a}, \mathrm{b}}$ & $3.53(0.93)^{\mathrm{a}, \mathrm{b}}$ & 0.99 \\
\hline Rules are fair & $3.02(1.26)^{\mathrm{a}, \mathrm{b}}$ & $4.22(0.87)^{\mathrm{a}, \mathrm{b}}$ & 0.98 & $2.96(1.15)^{\mathrm{a}, \mathrm{b}}$ & $3.87(0.98)^{\mathrm{a}, \mathrm{b}}$ & 0.80 \\
\hline $\begin{array}{l}\text { School is a nice } \\
\text { place }\end{array}$ & $3.12(1.25)^{\mathrm{b}}$ & $4.26(0.82)^{\mathrm{a}, \mathrm{b}}$ & 0.94 & $3.14(1.15)^{\mathrm{b}}$ & $3.55(1.03)^{\mathrm{a}, \mathrm{b}}$ & 0.36 \\
\hline $\begin{array}{l}\text { Belong at this } \\
\text { school }\end{array}$ & $3.27(1.29)^{\mathrm{b}}$ & $3.94(1.01)^{\mathrm{a}, \mathrm{b}}$ & 0.53 & $3.29(1.23)^{\mathrm{b}}$ & $3.55(1.07)^{\mathrm{a}, \mathrm{b}}$ & 0.21 \\
\hline \multicolumn{7}{|l|}{ Teachers } \\
\hline $\begin{array}{l}\text { Encouraged to } \\
\text { express own view }\end{array}$ & $3.47(1.15)^{\mathrm{a}, \mathrm{b}}$ & $4.36(0.72)^{\mathrm{a}, \mathrm{b}}$ & 0.80 & $3.58(1.07)^{\mathrm{a}, \mathrm{b}}$ & $3.93(0.97)^{\mathrm{a}, \mathrm{b}}$ & 0.33 \\
\hline Treat us fairly & $3.28(1.20)^{\mathrm{a}, \mathrm{b}}$ & $4.36(0.88)^{\mathrm{a}, \mathrm{b}}$ & 0.92 & $3.23(1.09)^{\mathrm{a}, \mathrm{b}}$ & $3.89(0.98)^{\mathrm{a}, \mathrm{b}}$ & 0.61 \\
\hline $\begin{array}{l}\text { Extra help when } \\
\text { needed }\end{array}$ & $3.72(1.12)^{b}$ & $4.34(0.77)^{\mathrm{a}, \mathrm{b}}$ & 0.57 & $3.75(0.99)^{\mathrm{b}}$ & $4.07(0.85)^{\mathrm{a}, \mathrm{b}}$ & 0.33 \\
\hline Interested in me & $3.34(1.18)^{\mathrm{a}}$ & $3.34(1.08)$ & 0.00 & $3.23(1.08)^{\mathrm{a}}$ & $3.47(1.11)$ & 0.22 \\
\hline $\begin{array}{l}\text { Not expect too } \\
\text { much }\end{array}$ & $3.11(1.27)^{\mathrm{a}, \mathrm{b}}$ & $3.79(0.99)^{\mathrm{a}, \mathrm{b}}$ & 0.55 & $3.04(1.13)^{\mathrm{a}, \mathrm{b}}$ & $3.60(0.95)^{\mathrm{a}, \mathrm{b}}$ & 0.50 \\
\hline \multicolumn{7}{|l|}{ Peers } \\
\hline $\begin{array}{l}\text { Students enjoy } \\
\text { together }\end{array}$ & $3.44(1.09)^{\mathrm{b}}$ & $3.98(1.21)^{\mathrm{a}, \mathrm{b}}$ & 0.49 & $3.40(0.94)^{b}$ & $3.62(1.15)^{\mathrm{a}, \mathrm{b}}$ & 0.23 \\
\hline Kind and helpful & $3.16(1.08)^{b}$ & $3.99(1.20)^{\mathrm{a}, \mathrm{b}}$ & 0.76 & $3.19(0.98)^{\mathrm{b}}$ & $3.58(1.22)^{\mathrm{a}, \mathrm{b}}$ & 0.39 \\
\hline $\begin{array}{l}\text { Other students } \\
\text { accept me }\end{array}$ & $3.69(1.24)^{\mathrm{a}, \mathrm{b}}$ & $4.09(1.14)^{\mathrm{a}, \mathrm{b}}$ & 0.33 & $3.80(1.10)^{\mathrm{a}, \mathrm{b}}$ & $3.53(1.14)^{\mathrm{a}, \mathrm{b}}$ & 0.24 \\
\hline
\end{tabular}

Note. Both means and standard deviations (in parentheses) are presented. ${ }^{a}$ indicates statistically significant difference between grade level within each country. ${ }^{\mathrm{b}}$ indicates statistically significant differences between country within grade level. The tests were based on $p<0.05$.

\subsection{Hypothesis 2: Chinese Adolescents Report More Positive Attitude towards Parental Involvement than American Adolescents}

Against the initial hypothesis, US students in both $7^{\text {th }}$ and $10^{\text {th }}$ grades reported significantly more positive perception in three out of four items, whereas Chinese students reported significantly more positive perception in only one item (My parents expect too much of me at school). In addition, there is clearly a developmental trend unique to the Chinese sample. Across all items on education environment, $10^{\text {th }}$ grade students are less positive about education environment than their counterparts in $7^{\text {th }}$ grade. 
Table 4. Mean, standard deviation, and effect size of perceived parental involvement by grade and country

\begin{tabular}{lllllll}
\hline & \multicolumn{3}{c}{$7^{\text {th }}$ Grade } & \multicolumn{3}{c}{$10^{\text {th }}$ Grade } \\
\cline { 2 - 7 } & U.S. & China & Cohen's $d$ & U.S. & China & Cohen's $d$ \\
\hline $\begin{array}{l}\text { Ready to help } \\
\begin{array}{l}\text { Come and talk } \\
\text { to teachers }\end{array}\end{array}$ & $4.11(1.36)^{\mathrm{b}}$ & $4.02(1.32)^{\mathrm{a}, \mathrm{b}}$ & 0.07 & $4.13(1.25)^{\mathrm{b}}$ & $3.57(1.48)^{\mathrm{a}, \mathrm{b}}$ & 0.44 \\
$\begin{array}{l}\text { Encouraged to } \\
\text { do well }\end{array}$ & $3.33(1.27)^{\mathrm{a}, \mathrm{b}}$ & 0.56 & $4.11(1.29)^{\mathrm{a}, \mathrm{b}}$ & $3.06(1.38)^{\mathrm{a}, \mathrm{b}}$ & 0.81 \\
$\begin{array}{l}\text { Not expect too } \\
\text { much }\end{array}$ & $3.57(1.08)^{\mathrm{b}}$ & $4.31(1.12)^{\mathrm{a}, \mathrm{b}}$ & 0.24 & $4.58(1.01)^{\mathrm{a}, \mathrm{b}}$ & $4.06(1.23)^{\mathrm{a}, \mathrm{b}}$ & 0.51 \\
& $3.82(1.05)^{\mathrm{b}}$ & 0.60 & $3.06(1.29)^{\mathrm{b}}$ & $3.75(1.03)^{\mathrm{b}}$ & 0.54
\end{tabular}

Note. Both means and standard deviations (in parentheses) are presented. ${ }^{a}$ indicates statistically significant difference between grade level within each country. ${ }^{\mathrm{b}}$ indicates statistically significant differences between country within grade level. The tests were based on $p<0.05$.

\subsection{Hypothesis 3: Chinese Adolescents Report More Positive Mental Health Status than American Adolescents}

The relationship between media consumption, especially TV viewing, and school performance has been extensively studied. In recent years, computer use may have replaced TV viewing as the most frequent form of media use. Table 5 shows that US adolescents spent more time watching TV, playing computer games and using computer for other purposes than their Chinese peers in grades 7 and 10 . Not surprisingly, $10^{\text {th }}$ graders reported less TV viewing than $7^{\text {th }}$ graders in both countries.

Table 5. Mean, standard deviation, and effect size of reported TV watching and computer use by grade and country

\begin{tabular}{lllllll}
\hline & \multicolumn{3}{c}{$7^{\text {th }}$ Grade } & \multicolumn{3}{c}{$10^{\text {th }}$ Grade } \\
\cline { 2 - 7 } & U.S. & China & Cohen's d & U.S. & China & Cohen's d \\
\hline $\begin{array}{l}\text { Daily } \\
\text { watching }\end{array}$ & $4.10(1.25)^{\mathrm{a}, \mathrm{b}}$ & $3.47(1.36)^{\mathrm{a}, \mathrm{b}}$ & 0.50 & $3.73(1.22)^{\mathrm{a}, \mathrm{b}}$ & $2.68(1.53)^{\mathrm{a}, \mathrm{b}}$ & 0.84 \\
$\begin{array}{l}\text { Weekly } \\
\text { computer games }\end{array}$ & $2.51(1.42)^{\mathrm{a}, \mathrm{b}}$ & $1.79(1.19)^{\mathrm{b}}$ & 0.52 & $2.11(1.28)^{\mathrm{a}, \mathrm{b}}$ & $1.90(1.16)^{\mathrm{b}}$ & 0.17 \\
$\begin{array}{l}\text { Weekly use of } \\
\text { computer }\end{array}$ & $2.67(1.26)^{\mathrm{a}}$ & $2.00(0.919)$ & 0.54 & $2.87(1.39)^{\mathrm{a}, \mathrm{b}}$ & $1.86(0.72)^{\mathrm{b}}$ & 0.75 \\
\hline
\end{tabular}

Note. Both means and standard deviations (in parentheses) are presented. ${ }^{a}$ indicates statistically significant difference between grade level within each country. ${ }^{\mathrm{b}}$ indicates statistically significant differences between country within grade level. The tests were based on $p<0.05$.

Adolescents' mental health was also assessed with respect to general happiness, feelings of loneliness or helpless, and self-confidence. As presented in Table 6 , Chinese students in $7^{\text {th }}$ grade reported significantly more positive tone than their US counterparts in three out of four items. However, such difference between the two countries was either weakened (general happiness) or completely reversed (feelings of loneliness or helpless, self-confidence) among $10^{\text {th }}$ graders. Again, there was no significant gender difference observed between grades or countries (data not shown). 
Table 6. Mean, standard deviation, and effect size of reported mental health status by grade and country

\begin{tabular}{lllllll}
\hline & \multicolumn{3}{c}{$7^{\text {th }}$ Grade } & \multicolumn{3}{c}{$10^{\text {th }}$ Grade } \\
\cline { 2 - 7 } & U.S. & China & Cohen's $d$ & U.S. & China & Cohen's $d$ \\
\hline $\begin{array}{l}\text { Happy } \\
\text { about life }\end{array}$ & $3.10(0.81)^{\mathrm{b}}$ & $3.47(0.63)^{\mathrm{a}, \mathrm{b}}$ & 0.47 & $3.00(0.79)^{\mathrm{a}, \mathrm{b}}$ & $3.13(0.79)^{\mathrm{a}, \mathrm{b}}$ & 0.16 \\
Not lonely & $3.12(0.85)^{\mathrm{b}}$ & $3.26(0.73)^{\mathrm{a}, \mathrm{b}}$ & 0.17 & $3.02(0.84)^{\mathrm{a}, \mathrm{b}}$ & $2.89(0.76)^{\mathrm{a}, \mathrm{b}}$ & 0.16 \\
Not helpless & $3.97(1.20)^{\mathrm{a}}$ & $4.07(0.98)^{\mathrm{a}}$ & 0.09 & $3.90(1.12)^{\mathrm{a}, \mathrm{b}}$ & $3.43(1.05)^{\mathrm{a}, \mathrm{b}}$ & 0.42 \\
Confident & $3.74(1.29)$ & $3.83(1.18)^{\mathrm{a}}$ & 0.07 & $3.69(1.16)^{\mathrm{b}}$ & $3.08(1.20)^{\mathrm{a}, \mathrm{b}}$ & 0.52
\end{tabular}

Note. Both means and standard deviations (in parentheses) are presented. ${ }^{a}$ indicates statistically significant difference between grade level within each country. ${ }^{\mathrm{b}}$ indicates statistically significant differences between country within grade level. The tests were based on $p<0.05$.

Cronbach's $\alpha$ revealed good internal consistency of individual items within the four core elements of education environment: school 0.792 , teacher 0.779 (one item, "My teacher expect too much of me at school", was removed), peer 0.752 , and parent 0.798 (one item, "My parents expect too much of me at school", was removed). Averages of individual items were then calculated for each of the four core elements. Pearson's $r$ revealed moderate connections among them (data not shown), but these four elements were considered sufficiently independent to be entered separately in a multivariate logistic regression model. Also included in the model were computer use (TV viewing was removed) and country. Table 7 shows that school, teacher, peer, parent, and country were all significant predictors of adolescents' mental health status.

Table 7. Logistic regression model testing association between adolescents' mental health status and education environment and computer use

\begin{tabular}{llll}
\hline & Adjusted Odds Ratio (AOR)* & $95 \%$ Confidence Interval (CI) & Significance \\
\hline School & 1.750 & $1.563-1.960$ & $p<0.001$ \\
Teacher & 1.182 & $1.064-1.313$ & $p<0.01$ \\
Peer & 1.654 & $1.509-1.812$ & $p<0.001$ \\
Parent & 1.381 & $1.289-1.480$ & $p<0.001$ \\
Computer use & 0.973 & $0.906-1.046$ & Not Sig. \\
Country & 0.645 & $0.471-0.882$ & $p<0.01$ \\
\hline
\end{tabular}

Note. ${ }^{*}$ Adjusted Odds Ratio (AOI) was controlled for all other variables in the model.

\section{Discussion}

The main purpose of the study was to examine cultural differences between China and the U.S. with respect to adolescents' perceptions of their education environment, their mental health status, and if new media and technology might have impact on their mental health. We tested three hypotheses by examining similarities and differences in perceived social behaviors and mental health between Chinese and American adolescents. This approach was grounded in cultural activity theory, because it provides a unifying and clarifying direction to the study of cross-cultural psychology and directs research focus on investigation of the interrelationships of social activities and psychology (Ratner, 2000).

\subsection{School Climate}

Significant difference was observed along three lines of perceived school climate -- school, teacher, and fellow students. In both grades 7 and 10, Chinese students reported significantly more positive perception in all items but one (My teachers are interested in me as a person). This is consistent with previous findings (Jia, Way, Ling, Yoshikawa, Chen, Hughes, Ke, \& Lu, 2009; Teddie \& Liu, 2008) and reflects a culture that supports education 
and respect teachers. Greenberger et al. (2003) also showed that Chinese students tend to be less tolerant and more disapproving of conduct problems. Interestingly, there is a developmental trend unique to the Chinese sample: $10^{\text {th }}$ grade students are less positive about school climate than their $7^{\text {th }}$ grade peers, which may reflect social activities to which adolescents in China are expected to devote themselves. As Chinese students move up the grade level, education becomes the number one priority in their lives. Given that doing well in school is of primary importance to Chinese adolescents, particularly during middle school, school may become less "fun" and "friendly" but more "demanding" and "monotone," thus leading to more negative connotations and implications. For example, poor performance in school means no opportunity to go to college, and student popularity and teacher approval are both based on academic achievement for the most part. This college-oriented cultural character and fewer options for Chinese students may be ultimately responsible for the declines in students' perception of school climate.

\subsection{Parental Involvement}

Surprisingly, in terms of parental involvement, American students in both grades reported significantly more positive perception than their Chinese peers in three out of four items. While communication between parents and adolescents tend to be more open in western cultures, Chinese parents demand compliance and obedience from adolescent starting in an early age. The enormous pressure put on adolescents to do well in school may take its toll on the parent-child relationship. Some of the difference is probably also due to social norms. Chinese parents consult with teachers or visit schools only when their children have academic problems or behaved improperly, thus requiring special attention. Parental visits to schools are rare and not considered positive events in Chinese culture.

As expected, American adolescents spend more time watching TV, playing computer games and using computer for other purposes than Chinese adolescents. Research has shown that children from low-income family have less access to computers than their more advanced peers (Attewell, Suazo-Garcia, \& Battle, 2003), although TV is available in the majority of families in both China and U.S. Parental involvement is also considered critical, because children are dependent on them for both access and use of media.

\subsection{Adolescent Mental Health}

Adolescents in China and U.S. were asked about their feelings of happiness, loneliness, helplessness, and self-confidence, which are essential ingredients and critical indicators of healthy development. Chinese students in $7^{\text {th }}$ grade reported significantly more positive tone than their U.S. peers. However, such difference between the two countries was either weakened (general happiness) or completely reversed (feelings of loneliness or helpless, self-confidence) among $10^{\text {th }}$ graders. The exactly same developmental pattern was also found in the perceptions of school climate, and therefore suggested that Chinese adolescents must experience major psychological transition in middle school. The question still remains as to what is the driving force behind this transition. More importantly, it reminds school and family to communicate with adolescents and understand their needs.

Results of regression analysis confirmed that school, teacher, peer, parent, and country were all significant predictors of adolescents' mental health status. Although computer use was not a significant predictor in the current analysis, other studies suggested that it could have both positive and negative impacts (Lee \& Peng, 2006; Van Evra, 2004) on adolescents.

\section{Conclusion, Limitations and Future Directions}

How do cultural activities affect adolescents' mental health? Although researchers have long been interested in cultural influences on development, there is still much to be known about the extent to which culture shapes adolescent social and mental behaviors. The current study revealed interesting developmental patterns among adolescents in China and U.S., and the findings suggested that many cultural factors discussed in this article are likely to account for the observed differences.

It should also be noted that the Chinese samples used in the current study were from an urban area in China. Given a great amount of variation across areas in China, generalization of the findings to other areas is limited. Also related to the samples was the imbalance of sample size, with a much larger number of American students than Chinese students. It may lower the power of some of the statistical analyses. In addition, the measures were self-reported and limited in their scope. Thus, these findings only served as a reference point from which a glimpse of cross-cultural psychological phenomena was captured.

Future studies, especially longitudinal studies, are needed to further explore the developmental trend identified in this article. Between-group comparisons within each country will validate culture-specific influences and may 
reveal additional differences. Last but not the least, new media and technology continues to be an indispensable part of adolescents' lives, and their impacts on mental health should be carefully monitored and evaluated.

\section{References}

Adelman, H. S., \& Taylor, L. (2006). Mental health in schools: Engaging learners, preventing problems, and improving schools. Thousand Oaks, CA: Corwin.

Agresti, A., Mehta, C. R., \& Patel, N. R. (1990). Exact Inference for contingency tables with ordered categories. Journal of the American Statistical Association, 85, 453-458. http://dx.doi.org/10.1080/01621459.1990.10476220

Anderson, C. A., \& Bushman, B. J. (2001). Effects of violent video games on aggressive behavior, aggressive cognition, aggressive affect, physiological arousal, and prosocial behavior: A meta-analytic review of the scientific literature. Psychological Science, 12(5), 353-359. http://dx.doi.org/10.1111/1467-9280.00366

Attewell, P., Battle, J., \& Suazo-Garcia, B. (2003). Computers and young children: Social benefit or social problem? Social Forces, 82(1), 277-296. http://dx.doi.org/10.1353/sof.2003.0075

Barber, B. K., \& Harmon, E. L. (2001). Violating the self: Parental psychological control of children and adolescents. In B. K. Barber (Ed.), Intrusive parenting: How psychological control affects children and adolescents (pp. 15-52). Washington, DC: American Psychological Association.

Barile, J. P., Donohue, D. K., Anthony, E. R., Baker, A. M., Weaver, S. R., \& Henrich, C. C. (2012). Teacher-student relationship climate and school outcomes: Implications for educational policy initiatives. Journal of Youth and Adolescence, 41(3), 256-267. http://dx.doi.org/10.1007/s10964-011-9652-8

Berkowitz, M. W., \& Bier, M. C. (2005). What works in character education: A report for policy makers and opinion leaders. Washington, D.C.: Character Education Partnership.

Brand, S., Felner, R., Shim, M., Seitsinger, A., \& Dumas, T. (2003). Middle school improvement and reform: Development and validation of a school-level assessment of climate, cultural pluralism, and school safety. Journal of Educational Psychology, 95(3), 570. http://dx.doi.org/10.1037/0022-0663.95.3.570

Brislin, R. W. (1986). The wording and translation of research instruments. In W. J. Lonner, \& J. W. Berry (Eds.), Field methods in cross-cultural psychology (pp. 137-164). Beverly Hills, CA: Sage.

Brown, B. B., Larson, R., \& Saraswathi, T. S. (Eds.). (2002). The world's youth: Adolescence in eight regions of the globe. http://dx.doi.org/10.1017/CBO9780511613814

Catalano, R. F., Haggerty, K. P., Oesterle, S., Fleming, C. B., \& Hawkins, J. D. (2004). The importance of bonding to school for healthy development: Findings from the Social Development Research Group. Journal of School Health, 74(7), 252-261. http://dx.doi.org/10.1111/j.1746-1561.2004.tb08281.x

Chen, C., \& Farruggia, S. (2002). Culture and adolescent development. In W. J. Lonner, D. L. Dinnel, S. A. Hayes \& D. N. Sattler (Eds.), Online readings in psychology and culture. Bellingham, WA: Center for Cross-Cultural Research, Western Washington University. Retrieved from http://www.wwu.edu/ culture

Chen, C., Greenberger, E., Farruggia, S., Bush, K., \& Dong, Q. (2003). The role of non-parental adults in adolescent development in China and the United States. Psychology in the Schools, 40, 35-50. http://dx.doi.org/10.1002/pits.10068

Cheung, S. K., \& McBride-Chang, C. (2007). Correlates of cross-sex friendship satisfaction in Hong Kong adolescents. International Journal of Behavioral Development, 31(1), 19-27. http://dx.doi.org/10.1177/0165025407073532

Cohen, J., McCabe, L., Michelli, N. M., \& Pickeral, T. (2009). School climate: Research, policy, practice, and teacher education. The Teachers College Record, 111(1), 180-213.

Cunningham, N. J. (2007). Level of bonding to school and perception of the school environment by bullies, victims, and bully victims. The Journal of Early Adolescence, 27(4), 457-478. http://dx.doi.org/10.1177/0272431607302940

Currie, C., Samdal, O., Boyce, W., \& Smith, R. (Eds.). (2001). Health behaviour in school-aged children: A WHO cross-national study (HBSC): Research protocol for the 2001/2002 survey. 
Donelan-McCall, N., \& Dunn, J. (1997). School work, teachers, and peers: The world of first grade. International Journal of Behavioral Development, 21(1), 155-178. http://dx.doi.org/10.1080/016502597385036

Hui, E. K., Sun, R. C., Chow, S. S. Y., \& Chu, M. H. T. (2011). Explaining Chinese students' academic motivation: filial piety and self-determination. Educational Psychology, 31(3), 377-392. http://dx.doi.org/10.1080/01443410.2011.559309

Jia, Y., Way, N., Ling, G., Yoshikawa, H., Chen, X., Hughes, D., ... Lu, Z. (2009). The influence of student perceptions of school climate on socioemotional and academic adjustment: A comparison of Chinese and $\begin{array}{llll}\text { American } \quad \text { adolescents. } & \text { Child }\end{array}$ http://dx.doi.org/10.1111/j.1467-8624.2009.01348.x

Kuperminc, G. P., Leadbeater, B. J., Emmons, C., \& Blatt, S. J. (1997). Perceived school climate and difficulties in the social adjustment of middle school students. Applied Developmental Science, 1(2), 76-88. http://dx.doi.org/10.1207/s1532480xads0102_2

Lan, W., \& Lanthier, R. (2003). Changes in students' academic performance and perceptions of school and self before dropping out of schools. Journal of Education for Students Placed at Risk, 8(3), 309-332. http://dx.doi.org/10.1207/S15327671ESPR0803_2

Larson, R. W. (2002). Globalization, societal change, and new technologies: What they mean for the future of adolescence. Journal of Research on Adolescence, 12(1), 1-30. http://dx.doi.org/10.1111/1532-7795.00023

Lee, K. M., \& Peng, W. (2006). What do we know about social and psychological effects of computer games? A comprehensive review of the current literature. In P. Vorderer, \& J. Bryant (Eds.), Playing video games: Motives, responses, and consequences (pp. 327-345). Mahweh, NJ: Erlbaum.

Ma, H. K., Cheung, P. C., \& Shek, D. T. L. (2007). The relation of prosocial orientation to peer interactions, family social environment and personality of Chinese adolescents. International Journal of Behavioral Development, 31(1), 12-18. http://dx.doi.org/10.1177/0165025406073504

Margolin, B. H. (1988). Test for Trend in Proportions. In S. Kotz, \& N. L. Johnson (Eds.), Encyclopedia of Statistical Sciences (Vol. 9, pp. 334-336). New York, NY: John Wiley \& Sons.

Mortimer, J., \& Larson, R. (Eds.). (2002). The Changing Adolescent Experience: Societal Trends and the Transition to Adulthood. http://dx.doi.org/10.1017/CBO9780511613913

Neuman, S. B. (1995). Literacy in the television age: The myth of the TV effect. Greenwood Publishing Group.

Noonan, J. (2004). School climate and the safe school: Seven contributing factors. Educational Horizons, 83(1), 61-65.

Ratner, C. (2000). Outline of a coherent, comprehensive concept of culture. Cross-Cultural Psychology Bulletin, 34(1 \& 2), 5-11. http://dx.doi.org/10.1177/1354067X0061001

Ratner, C. (2002). Cultural psychology: Theory and method. New York, NY: Kluwer Academic/Plenum Publishers. http://dx.doi.org/10.1007/978-1-4615-0677-5

Van Evra, J. (2004). Television and Child Development (3rd ed.). Mahwah, NJ: Lawrence Erlbaum Associates.

Teddlie, C., \& Liu, S. (2008). Examining teacher effectiveness within differentially effective primary schools in the People's Republic of China. School Effectiveness and School Improvement, 19(4), 387-407. http://dx.doi.org/10.1080/09243450802535182

Vazsonyi, A. T. (2003). Parent-adolescent relations and problem behaviors: Hungary, the Netherlands, Switzerland, and the United States. Marriage Family Review, 35, 161-187. http://dx.doi.org/10.1300/J002v35n03_09

Vygotsky, L. S. (1997). Collected works (Vol. 3). New York, NY: Plenum.

Wong, C. K., Wong, K. Y., \& Mok, B. H. (2006). Subjective well-being, societal condition and social policy: The case study of a rich Chinese society. Social Indicators Research, 78(3), 405-428. http://dx.doi.org/10.1007/s11205-005-1604-9

World Health Organization. (2003). Health behavior un school-aged children, 1997-1998. [United States] [Computer file] 
Xilong, C. (2006). Negative internet consuming behaviors of adolescents: Reasons and intervention. Journal of Jiangxi Finance College, 19(2), 59-60.

\section{Copyrights}

Copyright for this article is retained by the author(s), with first publication rights granted to the journal.

This is an open-access article distributed under the terms and conditions of the Creative Commons Attribution license (http://creativecommons.org/licenses/by/3.0/). 